\title{
Adding Bricks to Clicks: On the Role of Physical Stores in a World of Online Shopping
}

\section{Citation}

Avery, Jill, Thomas Steenburgh, John A. Deighton, and Mary Caravella. "Adding Bricks to Clicks: On the Role of Physical Stores in a World of Online Shopping." GfK Marketing Intelligence Review 5, no. 2 (November 2013).

\section{Published Version}

http://www.degruyter.com/view/j/gfkmir.2013.5.issue-2/gfkmir-2014-0015/

gfkmir-2014-0015.xml?format=INT

\section{Permanent link}

http://nrs.harvard.edu/urn-3:HUL.InstRepos:14485588

\section{Terms of Use}

This article was downloaded from Harvard University's DASH repository, and is made available under the terms and conditions applicable to Open Access Policy Articles, as set forth at http:// nrs.harvard.edu/urn-3:HUL.InstRepos:dash.current.terms-of-use\#OAP

\section{Share Your Story}

The Harvard community has made this article openly available.

Please share how this access benefits you. Submit a story.

\section{Accessibility}




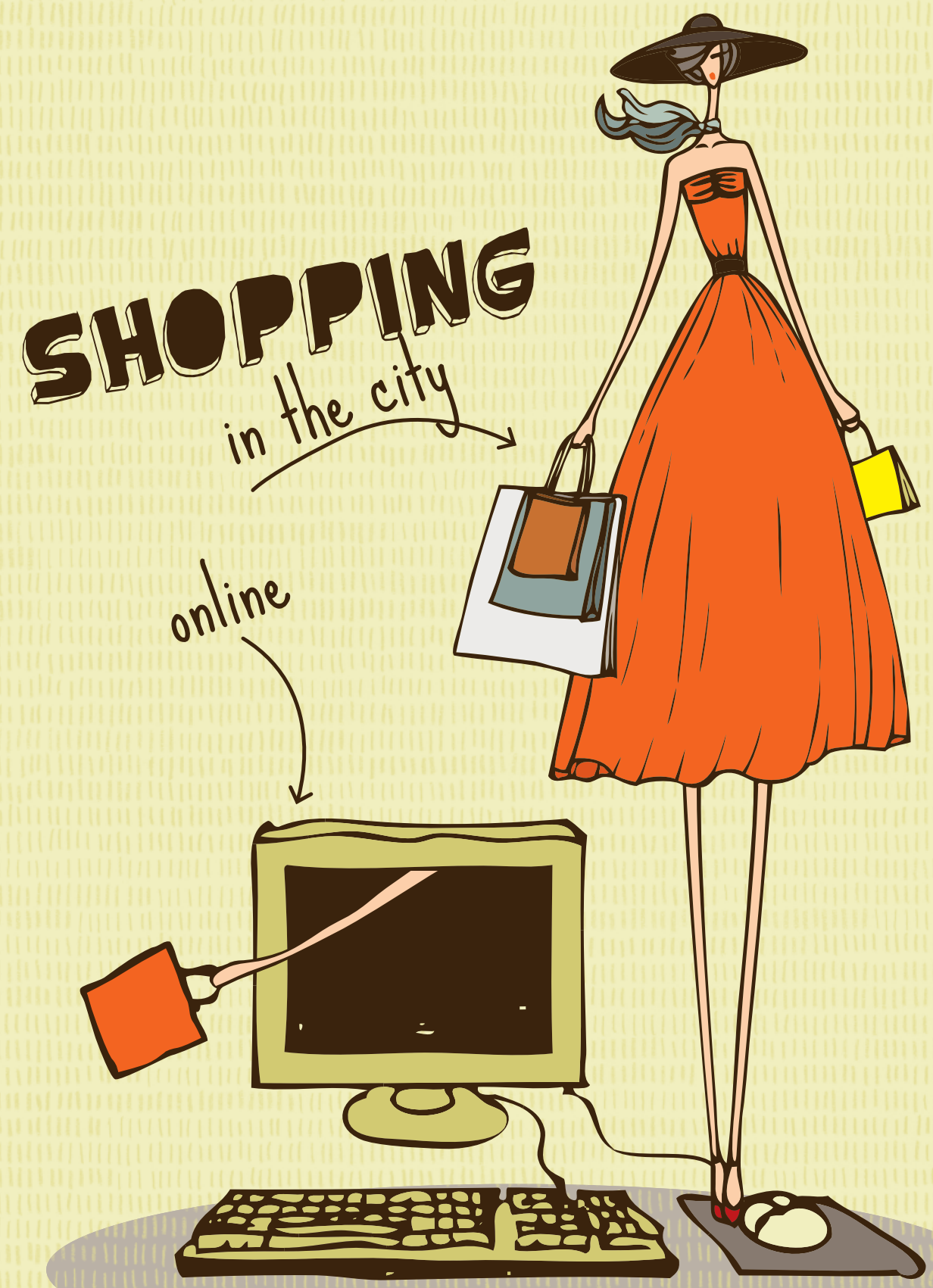




\title{
Adding Bricks to Clicks: On the Role of Physical Stores in a World of Online Shopping
}

\author{
Jill Avery, Thomas J. Steenburgh, John Deighton and Mary Caravella
}

KEYWORDS

Multichannel Retailing, Channel Management, Channel Migration, Direct

Marketing, E-Commerce, Retail Stores

THE AUTHORS

Jill Avery,

Harvard University,

javery@hbs.edu

Thomas J. Steenburgh,

University of Virginia,

SteenburghT@darden.virginia.edu

John Deighton,

Harvard Business School, Harvard University, ejdeighton@hbs.edu

Mary Caravella, University of Connecticut, mary.caravella@business.uconn.edu
Buying a product has never been easier. Consumers can shop online, over the phone or via mail order, from home or on the go, and if they want to experience touch and feel, they can also visit a "real" store. Often, one and the same retailer offers several of these options, and multichannel retailing has become common in most product categories. By offering several channels, retailers are trying to reach more consumer segments and create synergies, with stores acting as billboards for the brand, catalogs providing enticing reminders to buy and the Internet providing an ever-present storefront.

But synergies do not arise automatically. Different channels can also cannibalize one another, and it is not always easy to predict which effects will prevail. A recent study took a closer look at the interplay among different retail channels and showed that the short-term effects of store openings can be very different from the long-term sales impact.

\section{Analyzing the effects of store openings for a fashion} and home furnishings retailer // The researchers studied the effects of store openings of one multichannel retailer of fashion, home furnishings and high-end accessories. This retailer sold directly to consumers through catalogs and the Internet, as well as operated stores in shopping malls in some regions of the U.S. During the observation period - a timespan of nearly nine years - the retailer opened four new stores in the U.S. Two of the stores launched operations in retail trading areas previously served by only the direct channels, and two were opened in areas near a pre-existing retail store. 
FIGURE 1:

Comparing sales effects across channels in areas with and without new stores
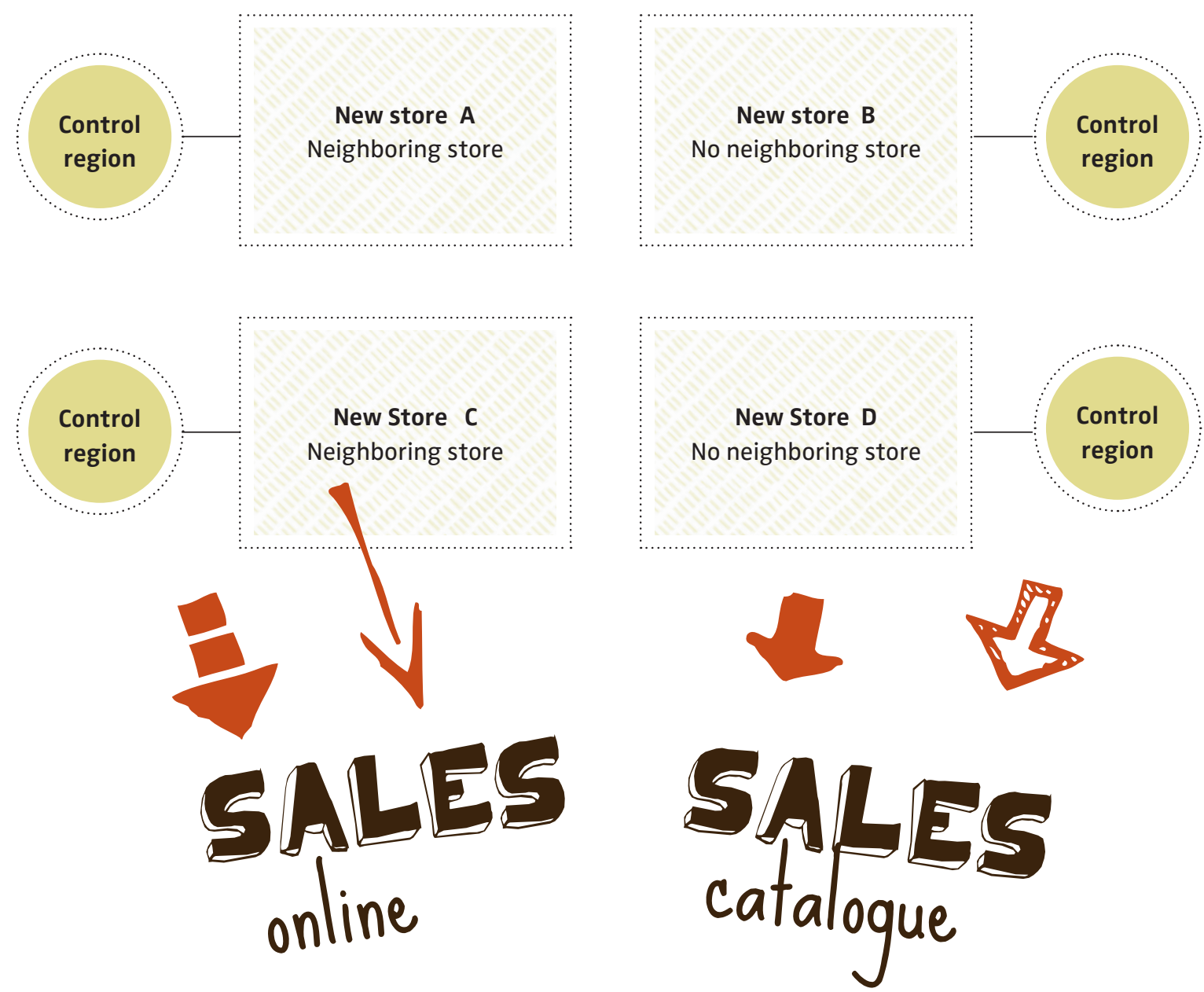

To isolate the effects of the store openings

or rule out alternative explanations for sales changes,

the control groups were actively composed

to match the group exposed to the store opening. 
FIGURE 2:

\section{Overview effects of additional stores}

\begin{tabular}{l|l|l}
\hline & Short-term sales & Long-term sales \\
\hline Catalog channel & $\begin{array}{l}11.9 \% \text { drop within } \\
\text { first month }\end{array}$ & $\begin{array}{l}\text { Full recovery after } \\
79 \text { months, continued } \\
\text { growth thereafter }\end{array}$ \\
\hline Internet channel & No drop & $\begin{array}{l}\text { Growth effect of } \\
\text { store opening five } \\
\text { times greater than } \\
\text { for catalogs }\end{array}$ \\
\hline
\end{tabular}

\section{〉> \\ Over time, both channels \\ increasingly benefited from the \\ presence of the new \\ brick-and-mortar stores.}

$\ll$
The study documents how sales in all channels reacted to the opening of the new stores by comparing them with a control sample that matches each group on several relevant criteria (geographic, demographic, behavioral, sales and competitive variables as well as marketing activity). Online and catalog orders originating from the regions where the new stores were located were assigned to four groups. All purchasers with resident ZIP codes within a maximum of 60 minutes driving time to the nearest new store were selected.

\section{Complementary effects outbalance channel cannibaliza-}

tion // The opening of brick-and-mortar stores by this retailer had positive and negative effects, but complementary consequences clearly outbalanced sales drops in individual channels:

$>$ In the short run, only catalog sales declined in the trading areas of the new stores. They dropped by $11.9 \%$ on average shortly after the brick-and-mortar stores opened.

$>$ Internet channel sales did not drop after the stores opened for business.
$>$ Over time, both channels increasingly benefited from the presence of the new brick-and-mortar stores. Within 79 months, catalog sales recovered to the level that would have been expected had the store never opened and subsequently continued growing more than in the sample without new stores.

> The store openings had a greater positive impact on the Internet channel than on the catalog channel. Its complementary effect was approximately five times larger.

$>$ Interestingly, areas with pre-existing stores gained more from the additional store than virgin territory. Obviously, branding effects from the two stores added up, significantly impacting brand awareness. The existence of additional stores seemed to support the brand image and accelerate growth. Research results showed that having more stores in an area can offer value for online sales as well. Store placement decisions should therefore reflect these effects in addition to calculations indicating whether an area can generate incremental sales to cover costs. 


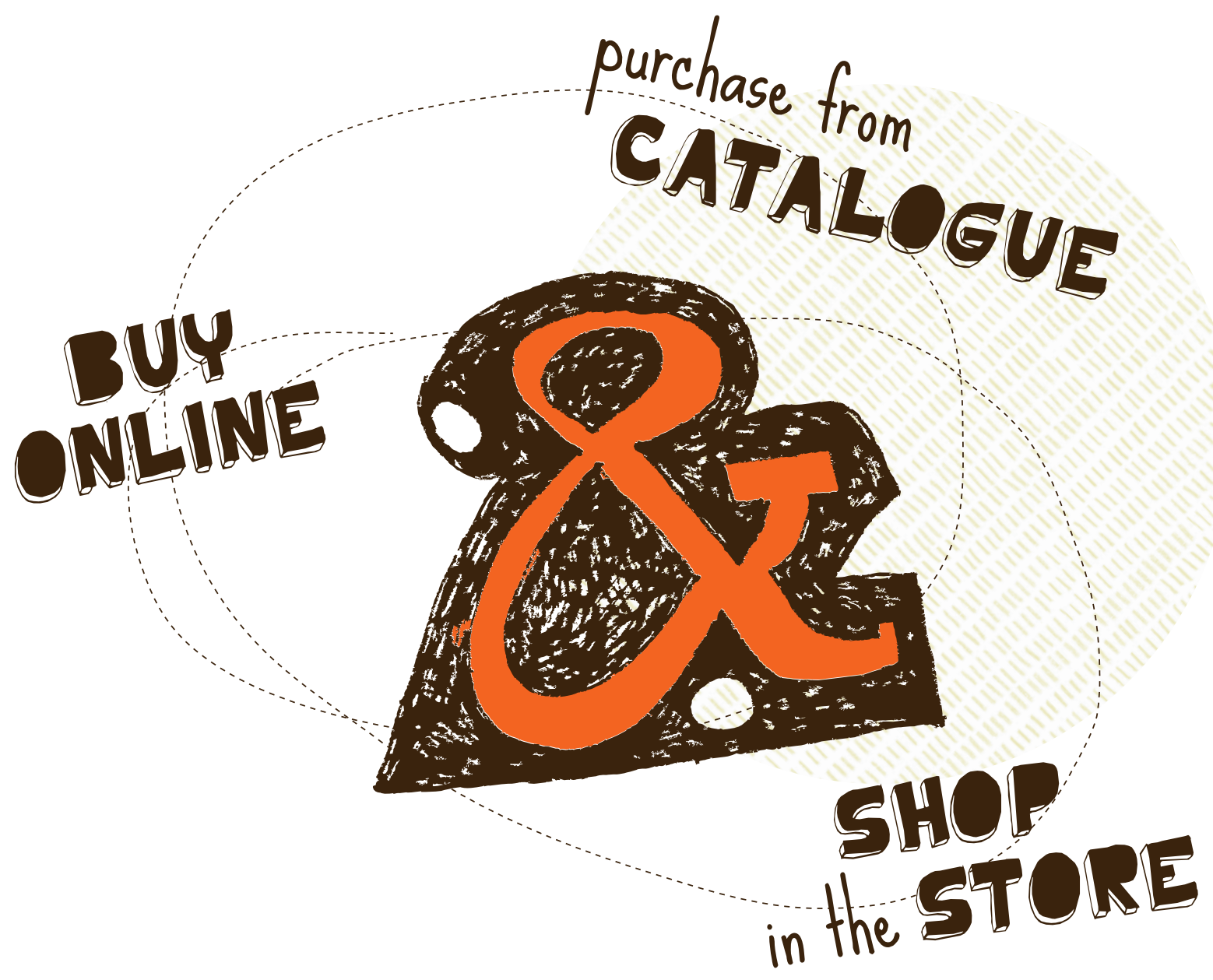

$>$ The number of first-time customers shopping via direct channels was not immediately affected by the opening of retail stores but did increase over time. The store seemed to act as a billboard for the direct channels by attracting new customers to the retailer at a faster rate than would have been expected had the store never opened.

> There was more cannibalization from the direct channels in areas without pre-existing stores. Some customers chose to try out the brand in the store instead of the direct channels in virgin territories, taking advantage of an opportunity they did not have before. In regions with pre-existing stores, this cannibalization seemed to have had occurred when the original store first opened. Over time, however, the new stores attracted customers to the brand at a faster rate in both types of territories.

\author{
$\gg$ \\ Tracking the dynamics \\ of store openings helps to implement \\ the desired effects \\ for the company and its customers.
}


Integrated channel management optimizes results // Even though this study involved only store openings by a single retailer with a well-established brand, some general implications are applicable across the board: A stronger understanding of positive and negative cross-channel effects helps retailers to better anticipate and respond to changes in sales in existing channels when a new one is added. It is the basis for strategically managing a company's channels as a portfolio rather than as separate entities.

An integrated approach to customer acquisition and relationship management benefits all parties. Tracking the dynamics of store openings helps to implement the desired effects for the company and its customers. In the case under review, the opening of a retail store had a small impact on the rate at which first-time customers used the direct channels in the short run. Therefore, managers of direct channels should continue to invest in customer acquisition programs during the months surrounding a new store opening if the retailer finds it more profitable to serve customers in the direct channels than in stationary stores. In the long term, retail stores increase the rate at which first-time direct channel customers are acquired. Thus, prospecting materials for new direct channel customers should include a retailer's brick-and-mortar store location and should highlight cross-channel benefits, such as the ability to pick up or return items ordered online at the store.

Adding brick-and-mortar stores creates more conflict with the catalog than with the online channel. In the short run, managers of catalog channels might be entitled to some temporary relief in their revenue targets because of the store openings to ensure their cooperation. In the long run, however, managers of catalog channels should be supportive of store openings. Catalog sales recover and ultimately benefit from the branding effects of the brick-and-mortar store.

Cross-channel promotions should be considered to leverage synergies. Given that stores enhance sales in the direct channels over time, promotions that encourage customers to shop across channels should be implemented. Cooperative cross-channel marketing can improve sales in all channels or drive sales from less profitable channels to more profitable ones. For example, if catalog cannibalization is undesirable to the retailer, it can offset drops in sales by increasing direct-channel promotions in the surrounding area during the store's opening period. This may keep existing customers in the catalog channel rather than entice them to shop in the store. In this case, the store becomes a customer acquisition engine, with its promotional vehicles targeted toward new, rather than existing, customers. Once customers are won over, communication can eventually direct them to the lower-cost catalog and online channels.

Models and algorithms used to drive catalog and other direct mailings to customers should reflect cross-channel effects in their decision-support systems to avoid a counterproductive decrease in marketing support. Traditional RFM models, which recommend catalog or direct-mail drops based on the recency, frequency and monetary (RFM) value of prior transactions, might lead to the implementation of counterproductive marketing activities. Retailers may decrease catalog mailings to customers who have temporarily switched some of their purchasing to the retail store channel. Particularly in the catalog channel, this decrease in marketing support may intensify the drop in sales and prolong the onset of synergistic effects. Retailers who understand the patterns of cross-channel interaction can adjust the algorithm and reinforce synergies.

\section{Managerial summary of an article published in the academic top journal "Journal of Marketing":}

Avery, Jill; Steenburgh, Thomas J.; Deighton, John;

Caravella, Mary (2012): "Adding Bricks to Clicks: Predicting the Patterns of Cross-Channel Elasticities over Time", Journal of Marketing, Vol. 76, No. 3 (May), pp. $96-111$. 